\title{
Experimental and simulation results of Optical Beam Induced Current Technique Applied to Wide Bandgap Semiconductors
}

\author{
Dominique Planson, Besar Asllani, Luong-Viet Phung, Pascal Bevilacqua, Hassan Hamad, Christophe Raynaud \\ Univ Lyon, INSA Lyon, Ecole Centrale de Lyon, Université Claude Bernard Lyon 1, CNRS, Ampère, F-69621, Villeurbanne, \\ France \\ *dominique.planson@insa-lyon.fr
}

\begin{abstract}
Power electronic devices based on wide bandgap (WBG) semiconductors such as silicon carbide (SiC), gallium nitride $(\mathrm{GaN})$ and diamond $(\mathrm{C})$ offer better performances when compared to those based on silicon $(\mathrm{Si})$. However, the peripheral protection of these devices must be carefully designed to sustain high voltage bias. This paper shows how the OBIC (Optical Beam Induced Current) technique applied to WBG semiconductor devices could be useful to study the efficiency of different protection techniques. Firstly, a theoretical approach is given to present the this electro-optical characterization method. Then, it is performed on high voltage power devices in a vacuum chamber allowing to study the spatial distribution of the electric field in the semiconductor. In addition, comparisons with Finite Elements Methods using TCAD tools are performed showing the local high electric field strength. Results are mainly focused on $\mathrm{SiC}$ devices for the sake of availability. This paper shows additional results and measurements on GaN and diamond Schottky diodes also. Finally, extraction of OBIC signals allows to know some physical features like ionization coefficients, minority carrier lifetime and local defects in semiconductors as shown in the last section.
\end{abstract}

Keywords: optical device characterization, power devices, Silicon Carbide, Gallium Nitride, Diamond.

\section{1 - Introduction}

Wide Bandgap semiconductors materials like Silicon Carbide ( $\mathrm{SiC})$ Gallium Nitride (GaN) and Diamond (C) have excellent properties for many applications especially for high voltage devices [1] [3]

Future smart grids and HVDC (High Voltage Direct Current) transmission energy topologies will soon require ultrahigh voltage devices $(>10 \mathrm{kV})$ [4]-[6]. In order to fully benefit the advantages of WBG semiconductors materials and avoid premature breakdown of the high voltage devices, it is mandatory to have efficient peripheral protections [7], [8]. This paper shows how the OBIC techniques can help to determine the efficiency of the periphery protection by analyzing the electric field distribution in the structure and especially at the junction periphery. A comparable technique to OBIC is EBIC (Electron Beam Induced Current) [9]. It enables the quick and accurate characterization of local electric field in the device where the built-in potential exists, but it is not applicable when devices are biased at high voltage.

\section{2 - Experimental OBIC setup}

A focused laser beam is used to generate electron-hole pairs (EHPs) into the semiconductor as shown in Fig. 1 for an infinite plane-parallel PN junction. Two semi-reflecting mirrors and a focusing lens are controlled with Labview software in order to get a focused spot at the surface of the semiconductor in the range of $60 \mu \mathrm{m}$ in diameter. The high voltage device under test (DUT) is placed in the vacuum chamber as shown in Fig. 2 and reverse biased with a high voltage power supply "FUG-HCN 140012500 " (up to $12.5 \mathrm{kV}$ ). The surface of the DUT is scanned in with a step of $10 \mu \mathrm{m}$ under high voltage. Current is measured with a microammeter (Keithley 6485). It allows to realize mapping of the induced current on a plane $(\mathrm{X}, \mathrm{Y})$ or only lines. The intensity of the spectra is related to the electric field and hence to the reverse voltage applied to the DUT. Thanks to the simulation software, it is possible to have a correlation with the electric field inside the device. The OBIC principle has already been described in [10], [11]. 


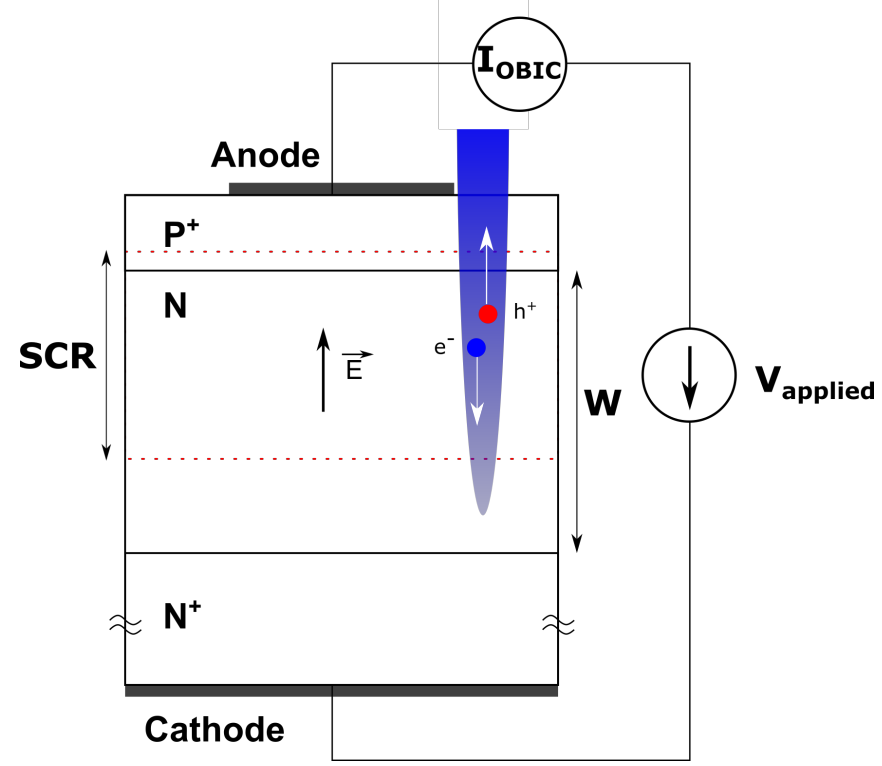

Fig. 1: Measurement principle of a reverse-biased parallel- plane infinite $\mathrm{P}^{+} \mathrm{N}$ junction. Carriers are generated along the laser beam and collected by the electrodes.
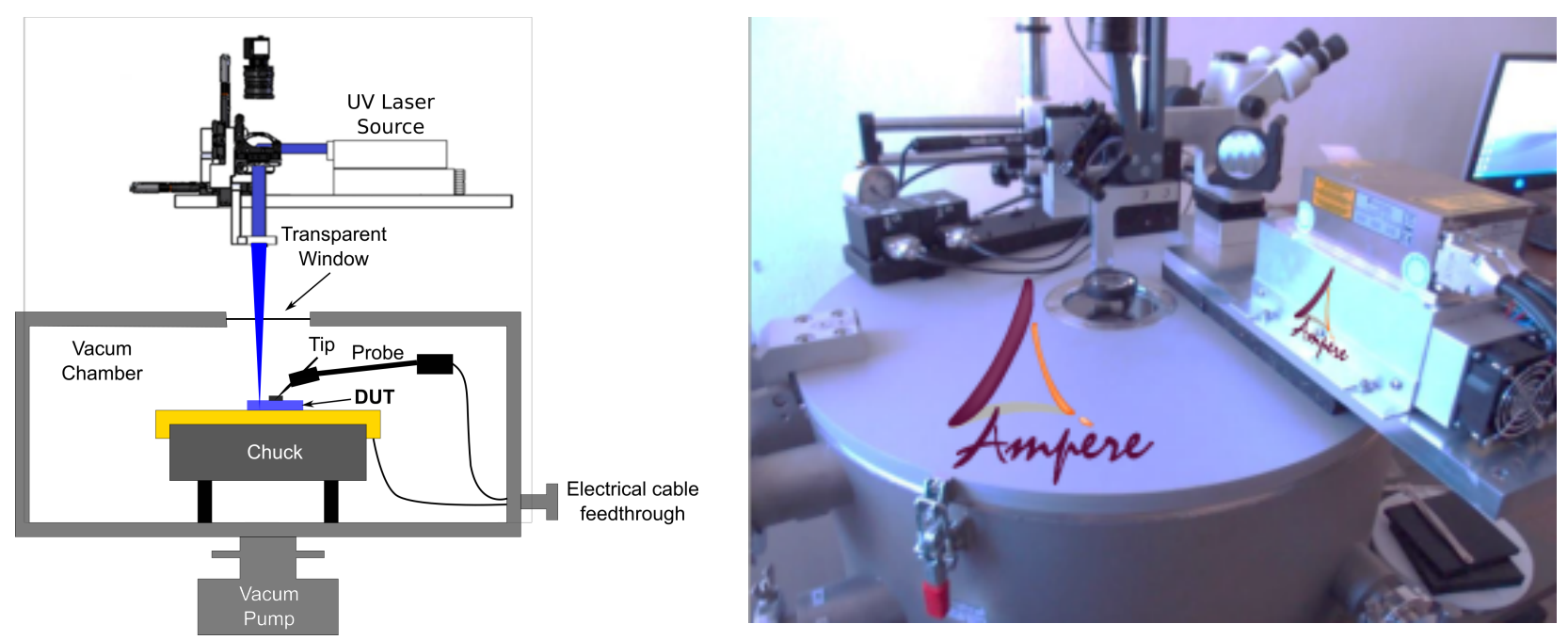

Fig. 2: Experimental OBIC bench with the DUT in the vacuum chamber (schematic on the left and picture of the actual setup on the right).

If the photon energy $\left(E_{\varphi}=h c / \lambda\right)$ of the laser beam is smaller than the bandgap energy $\left(E_{G}\right)$ of the semiconductor, two photons are required to ionize a dopant atom, that is the so-called two-photons absorption process. For this purpose, two different wavelengths are used, either the green $(\lambda=532 \mathrm{~nm})$ or UV $(\lambda=349 \mathrm{~nm})$, supplied by two pulsed semiconductor lasers. Two different workbenches have been developed adequately. Most of the measurements were performed with the UV laser, except for the results given in Section 6.3.

\section{3 - Simulation of OBIC structure}

Sentaurus TCAD is finite element simulation suite which allows for the simulations and design of semiconductor devices [12]. As such, the simulator has been used to simulate the devices measured in the next section. A particular attention has been accorded to the simulation of electric field and the OBIC current in the diode structure. For this purpose, 4 diode structures were built with the same geometry and doping parameters (see section 4.2), except for the peripheral protection. The physical parameters of the optical beam (diameter, spatial distribution and intensity) have been chosen to fit the experiments. 
The schematic cross sections of the 4 simulated devices are shown in figure 3.a). The different JTE structures have been simulated in order to find the optimal peripheral protection that would distribute the electric field lines far from the edge of anode and ensure a higher break down voltage. Figure 3.b) shows the distribution of the electric field at the edge of the peripheral protection. For both $400 \mu \mathrm{m}$ JTE and $500 \mu \mathrm{m}$ JTE the electric field peak happens wright at the edge of the $\mathrm{P}^{+}$anode, showing that the length of the JTE doesn't provide any benefits pas a critical value. The $400 \mu \mathrm{m}$ JTE assisted by 6 JTE rings is probably the optimal solution since all the rings contribute do the decreasing of the field crowding at the edge of the JTE. Whereas for the $400 \mu \mathrm{m}$ JTE assisted by 8 JTE rings, the electric field is distributed around the first 7 rings. This means that the last ring is not contributing to the protection, which in fact is a waste of material.
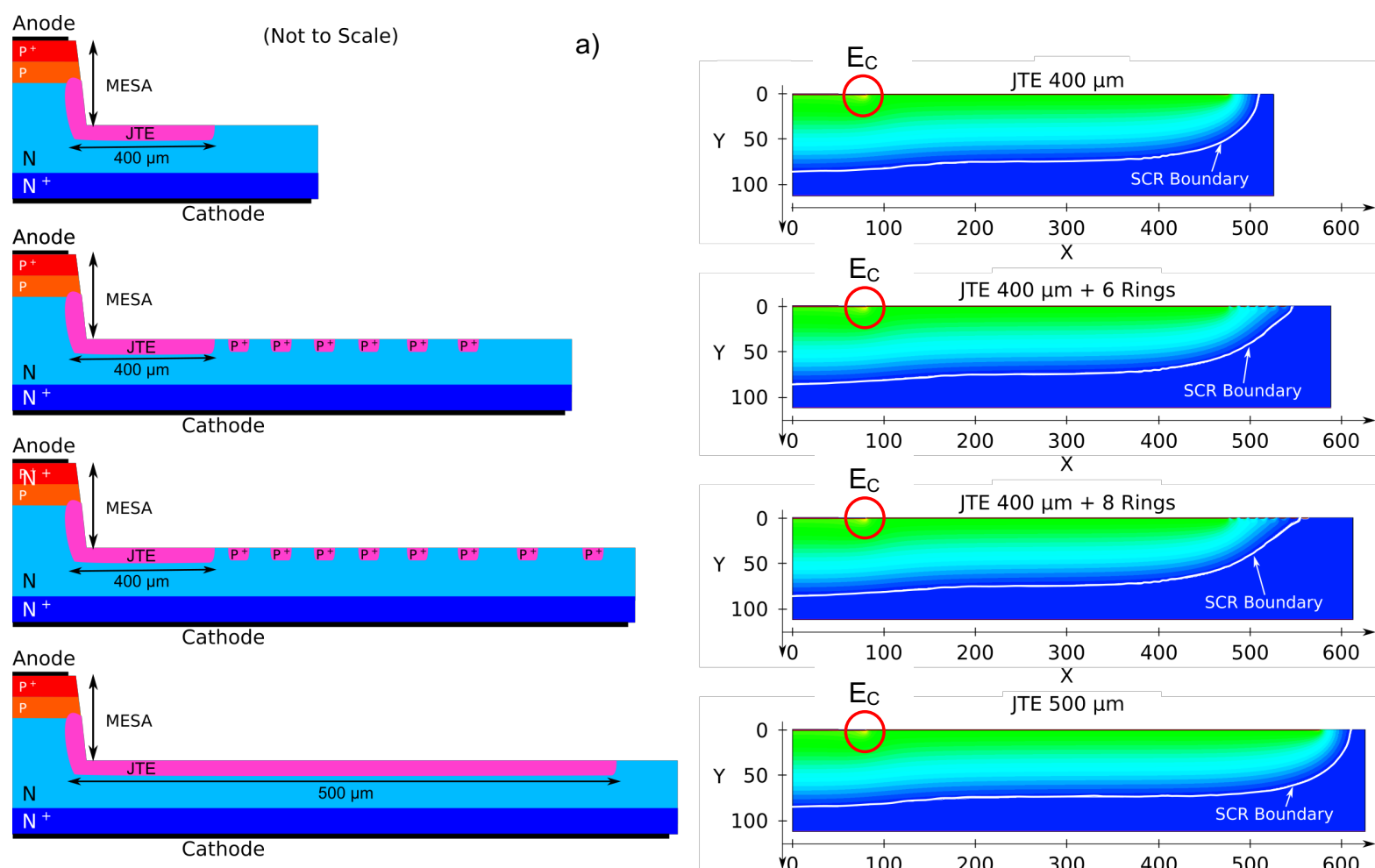

b)
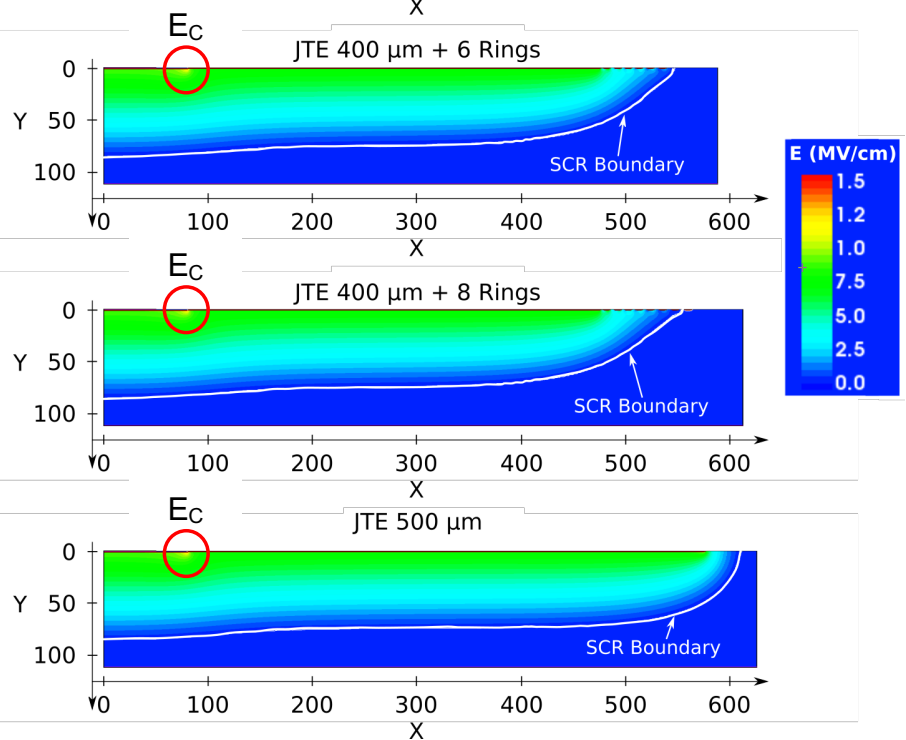

Fig. 3: Comparison of the schematic cross section of the 4 simulated structures MESA-JTE. The parameters are written on the drawings (left). Simulated electric field corresponding to $4800 \mathrm{~V}$ of reverse bias voltage. The critical electric field is reached at the periphery of the anode as the peripheral protection is not efficient in none of the simulated cases. White line is the limit of the Space Charge Region (right).

Nevertheless, the efficiency of the peripheral protection has to be compared to the 1D structure and can be found to be optimal above $80 \%$. This usually happens when the peaks of the electric field are equal at the edge of the anode and that of the peripheral protection. Figure 4 shows the distribution of the electric field for the 4 simulated structures. The electric field crowds at the edge of the JTE but also at the edge of the anode where the peak value is reached. The simulation results show that the JTE and the rings doping dose is lower than the optimal one. In order to confirm this hypothesis, OBIC measurements can be used to show the position of the electric field as the OBIC current is locally enhanced by the high electric field. As a matter of fact, electron hole pairs that are generated by the optical beam are accelerated by the electric field and can generate more electron hole pairs if their kinetic energy is high enough. 


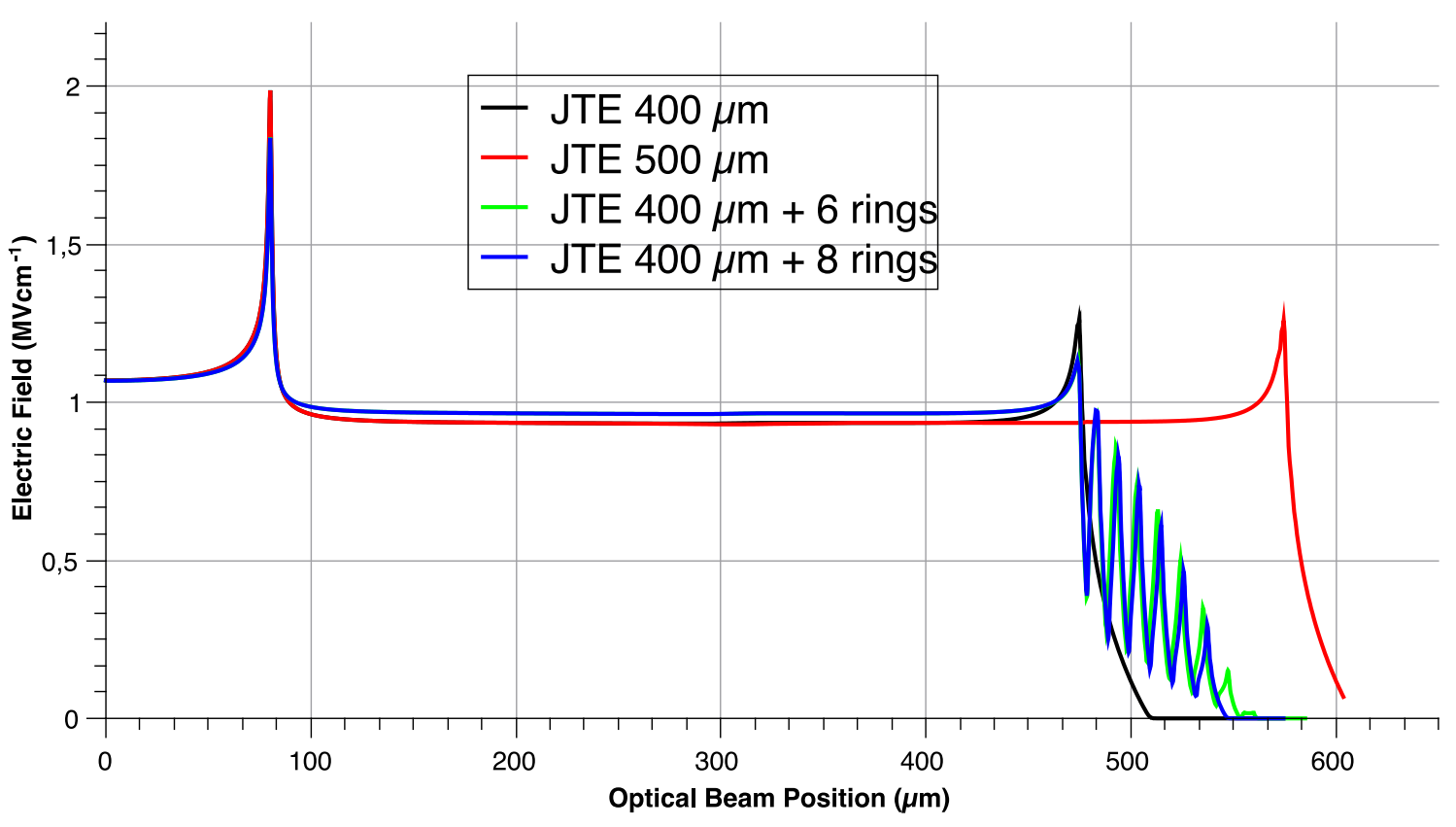

Fig. 4: Comparison of the electric field distribution along the x-axis of the 4 simulated structures

The results of the simulation of the OBIC current are shown in figure 5. The optical beam has been applied from right to left. The obtained OBIC signal is null in the areas where the electric field is low. As the beam encounters the electric field, the OBIC signal increases. The area where the highest electric field is found produces the higher signal and a difference can be seen in structures with only JTE or JTE assisted with rings. Since the electric field is better distributed by the ring assisted structures, the electric field is lower at the edge of the anode. For this reason, the OBIC current is higher at the structures with a simple JTE.

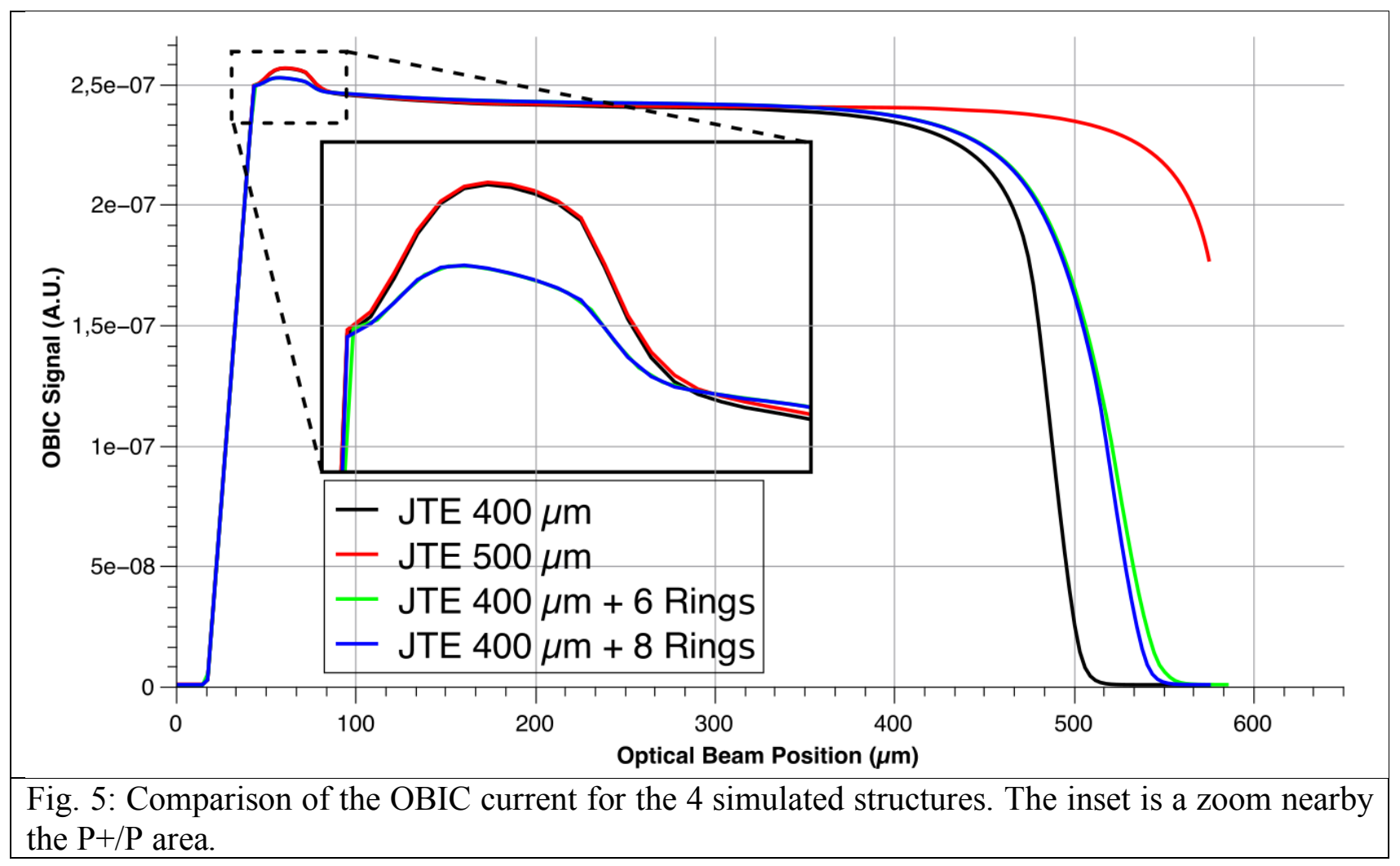


These results are very encouraging since they prove that OBIC measurements can be useful to design and test the peripheral protections of WBG power devices.

\section{4 - Measurement on $4 \mathrm{H}-\mathrm{SiC}$ PiN diodes}

A great number of structures have been studied, mostly with the aim to reach high voltage device. The first range is about a voltage capability of $3300 \mathrm{~V}$ of bipolar (PiN) diode.

4.1 - Medium voltage PiN diode (3.3 kV class).

Single JTE bipolar diodes with two doses (as described in Table 1) have been measured. A crosssection of the diode is shown in Fig. 6.

\begin{tabular}{|l|c|c|}
\hline & Device 1 & Device 2 \\
\hline JTE dose $\left[\mathrm{cm}^{-2}\right]$ & $1.23 \times 10^{13}$ & $6.84 \times 10^{12}$ \\
\hline Epilayer thickness $[\mu \mathrm{m}]$ & 40 & 30 \\
\hline Epilayer doping $\left[\mathrm{cm}^{-3}\right]$ & $1.04 \times 10^{15}$ & $9.95 \times 10^{14}$ \\
\hline Simulated breakdown voltage $[\mathrm{V}]$ & 2956 & 2922 \\
\hline
\end{tabular}

Table 1: Details of the 2 types of the tested devices

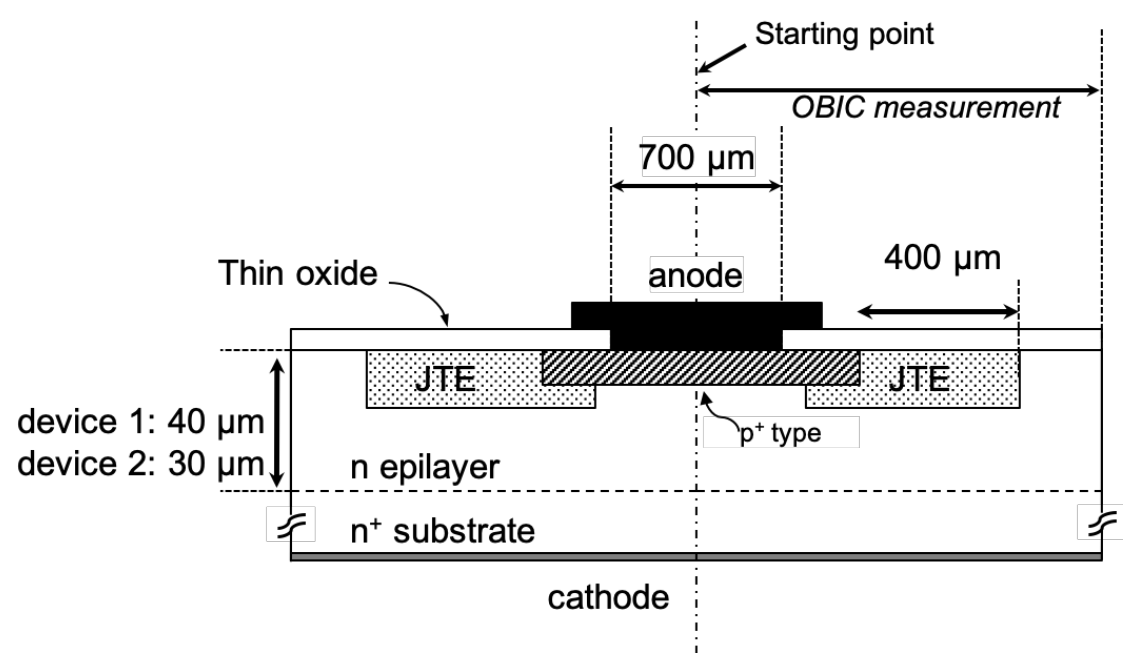

Fig. 6: Cross section of the planar PiN JTE protected diode

OBIC measurements have been performed on both devices namely device 1 and device 2 with the UVlaser. Applied reverse voltages range between 800 and $2850 \mathrm{~V}$ depending of the breakdown voltage. For device 1 with the highest JTE dose, the enhancement of the OBIC current is located near the edge of the JTE. On the contrary, with device 2, the lowest JTE dose, the enhancement of the OBIC current is located near the P+/JTE area, as it could be observed on the Figure 7 . Location of the metallization, $\mathrm{P}+$ and JTE areas are mentioned at the bottom of the graphs. 


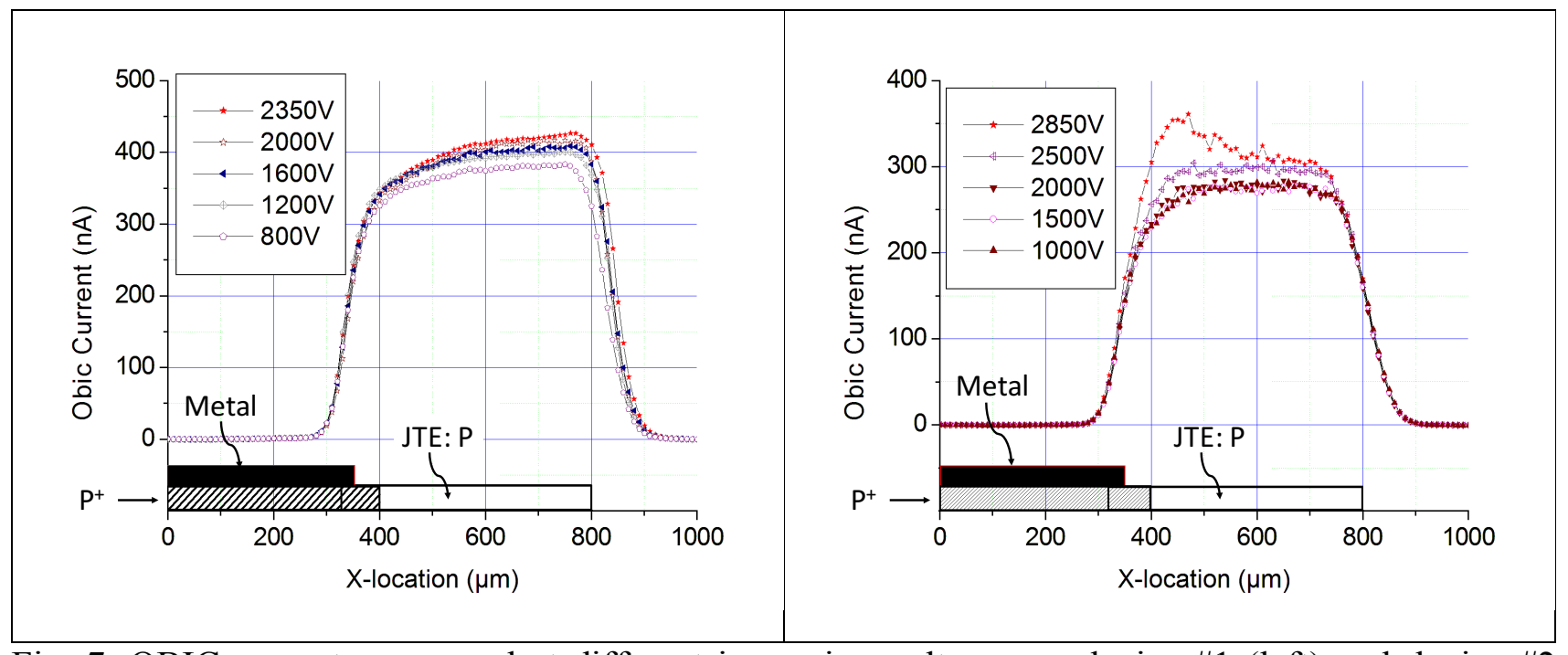

Fig. 7. OBIC currents measured at different increasing voltages on device \#1 (left) and device \#2 (right). Measurements are done only on the right-hand side of the device.

Near breakdown voltage (refer to simulated value in Table 1) induces high electric field, which leads to an enhancement of the OBIC signal.

\section{2 - High voltage PiN diode (10 kV class).}

High voltage PiN diodes were fabricated on a $4 \mathrm{H}-\mathrm{SiC}$ wafer using a $110 \mu \mathrm{m}$ thick epilayer with a doping concentration of $7 \times 10^{14} \mathrm{~cm}^{-3}$. These diodes are MESA-JTE protected with or without JTE-ring (6 or 8 rings), as shown in Fig. 8.

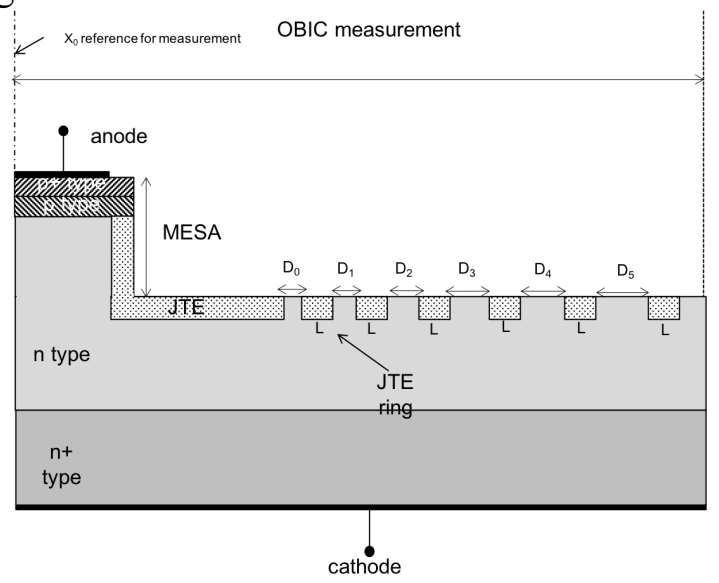

Fig. 8. Cross section of the right half part of high voltage bipolar PiN diode MESA protected with 6 JTE rings.

Prior to OBIC measurements, reverse IV characteristics were performed to determine the near breakdown voltage. High voltage OBIC measurements were performed in 1D-sweeping mode with a step of $10 \mu \mathrm{m}$ for increasing voltages. 4 kinds of diodes were measured (400 $\mu \mathrm{m}$ JTE length, $400 \mu \mathrm{m}$ JTE length with 6 JTE-rings, $400 \mu \mathrm{m}$ JTE length with 8 JTE-rings and finally $500 \mu \mathrm{m}$ JTE length). As the voltage increases, and aproaches the breakdown voltage, one can observe the birth of an OBIC peak located near the P+/JTE area in Figures 9 to 12. This is due to the electric field enhancement at the $\mathrm{P}^{+} / \mathrm{JTE}$ overlap, meaning that the JTE dose is too low. Moreover, breakdown voltages are far from the theoretical breakdown voltage $(10 \mathrm{kV})$, which implies a poor efficiency of the peripheral protection. 


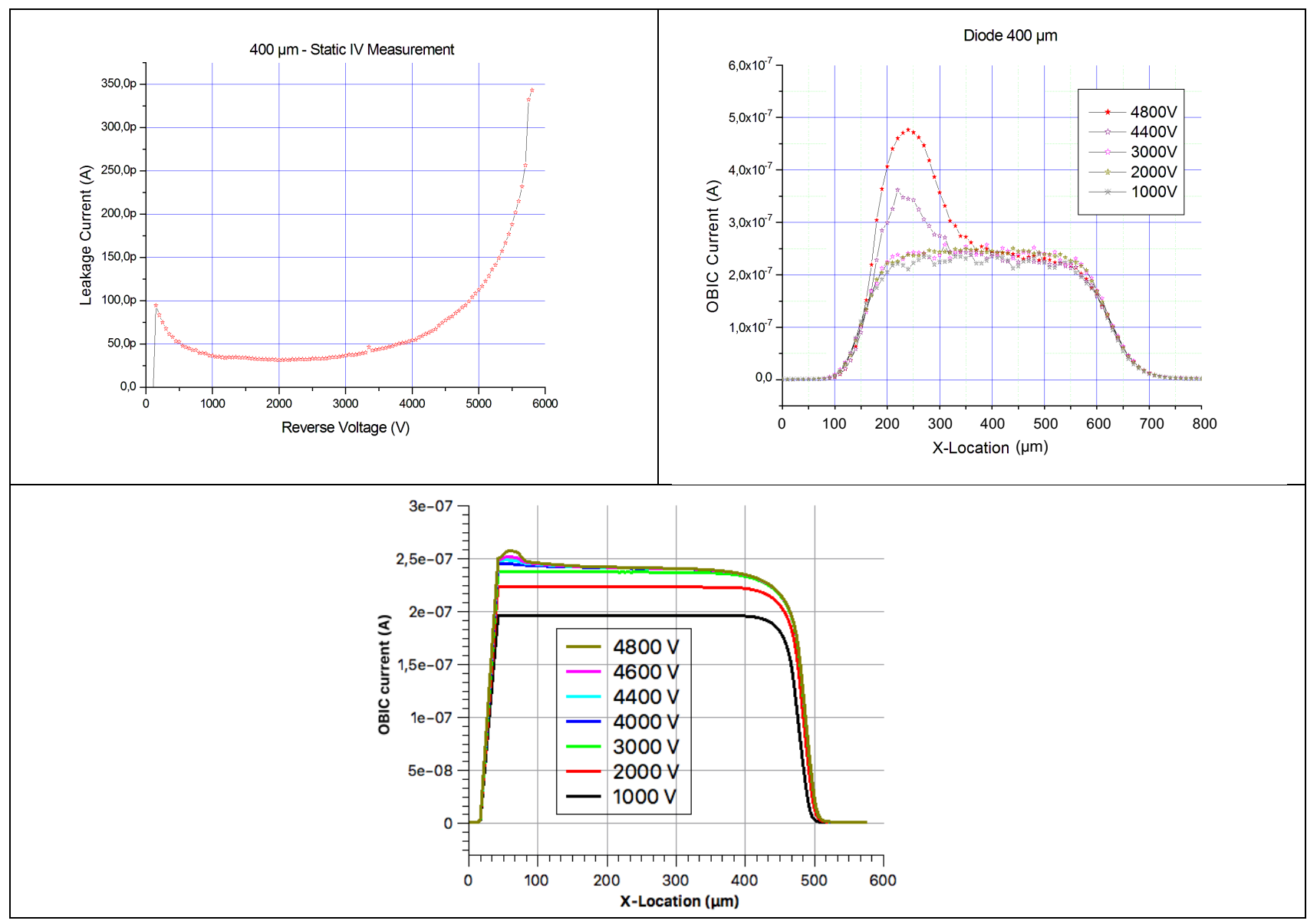

Fig. 9. Reverse experimental IV characteristics (upper left), 1D-sweeping OBIC measurements (upper right), 1D-sweeping OBIC simulations for several reverse biases (bottom) of the $\mathbf{4 0 0} \boldsymbol{\mu m}$ MESA JTE protected diode.

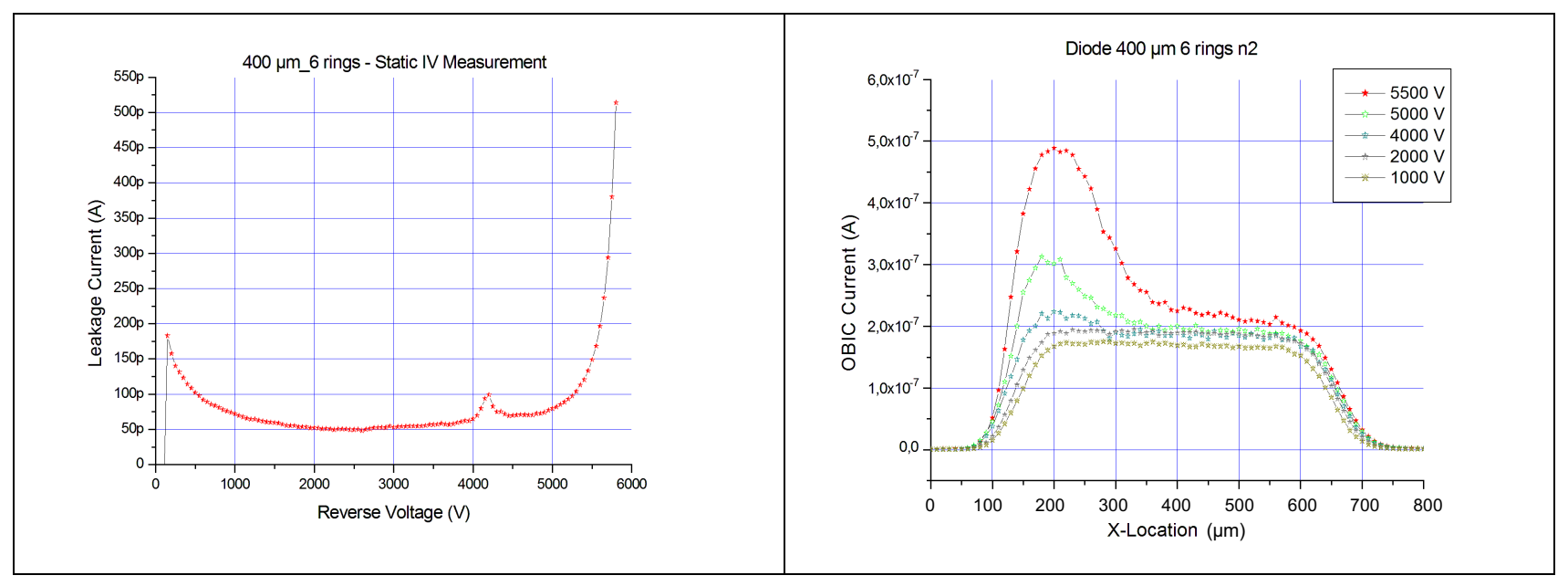




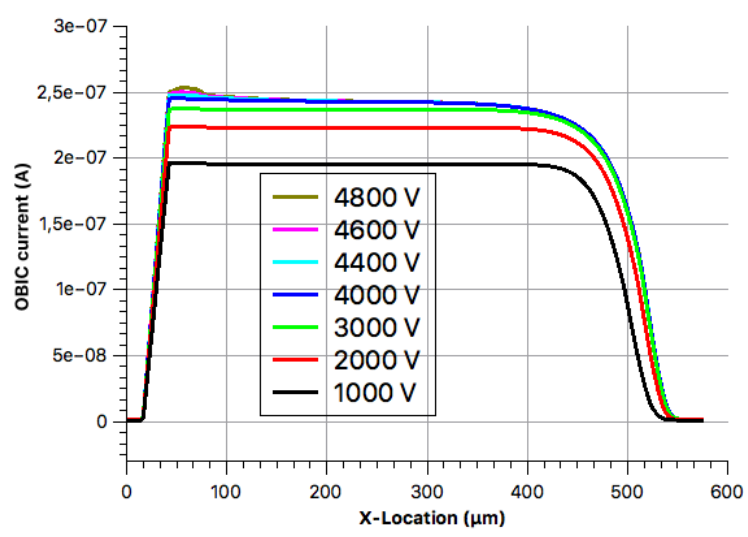

Fig. 10. Reverse experimental IV characteristics (upper left), 1D-sweeping OBIC measurements (upper right), 1D-sweeping OBIC simulations for several reverse biases (bottom) of the $\mathbf{4 0 0} \boldsymbol{\mu m}$ MESA-JTE +6 rings protected diode.

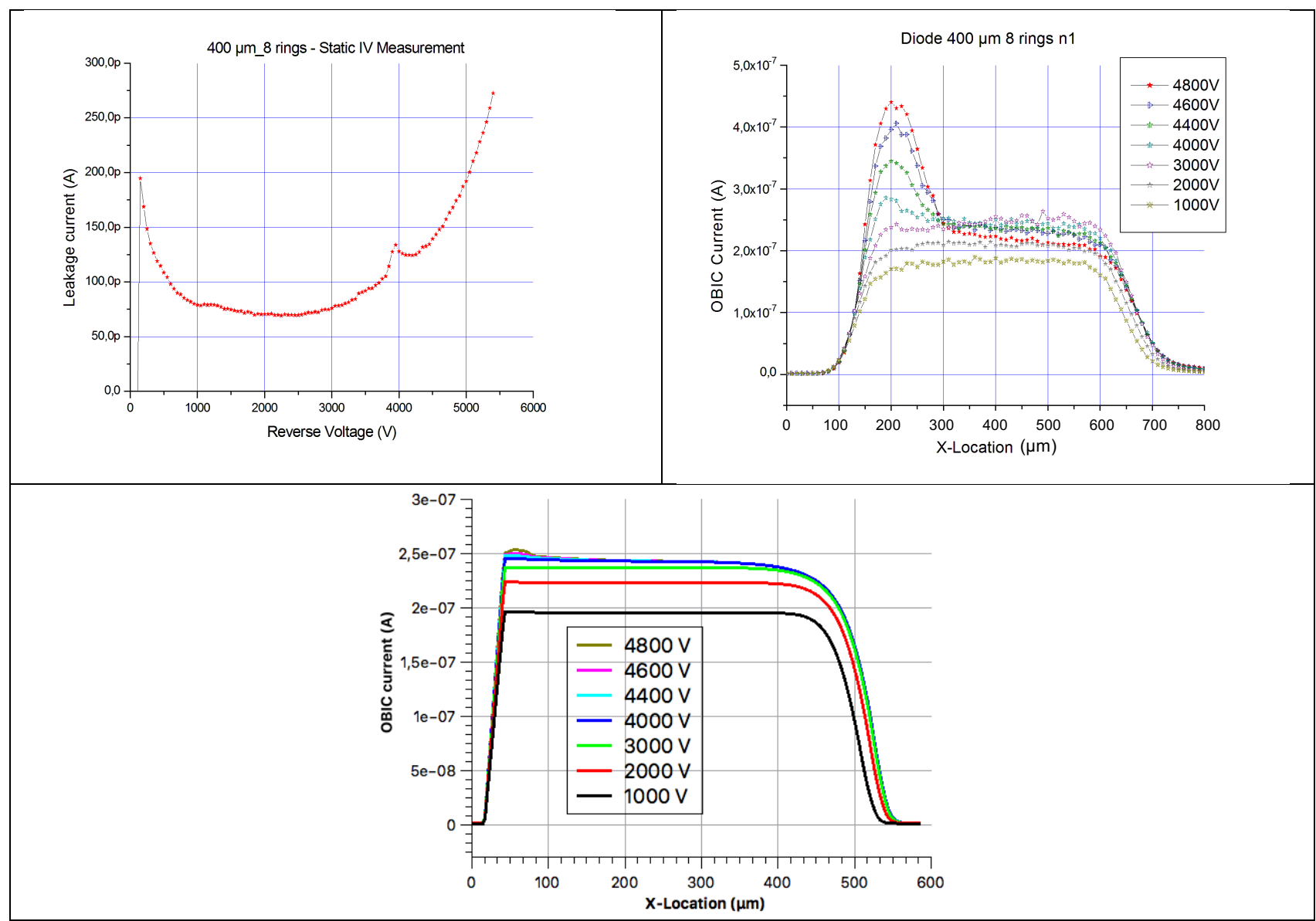

Fig. 11. Reverse experimental IV characteristics (upper left), 1D-sweeping OBIC measurements (upper right), 1D-sweeping OBIC simulations for several reverse biases (bottom) of the $\mathbf{4 0 0} \boldsymbol{\mu m}$ MESA-JTE +8 rings protected diode. 


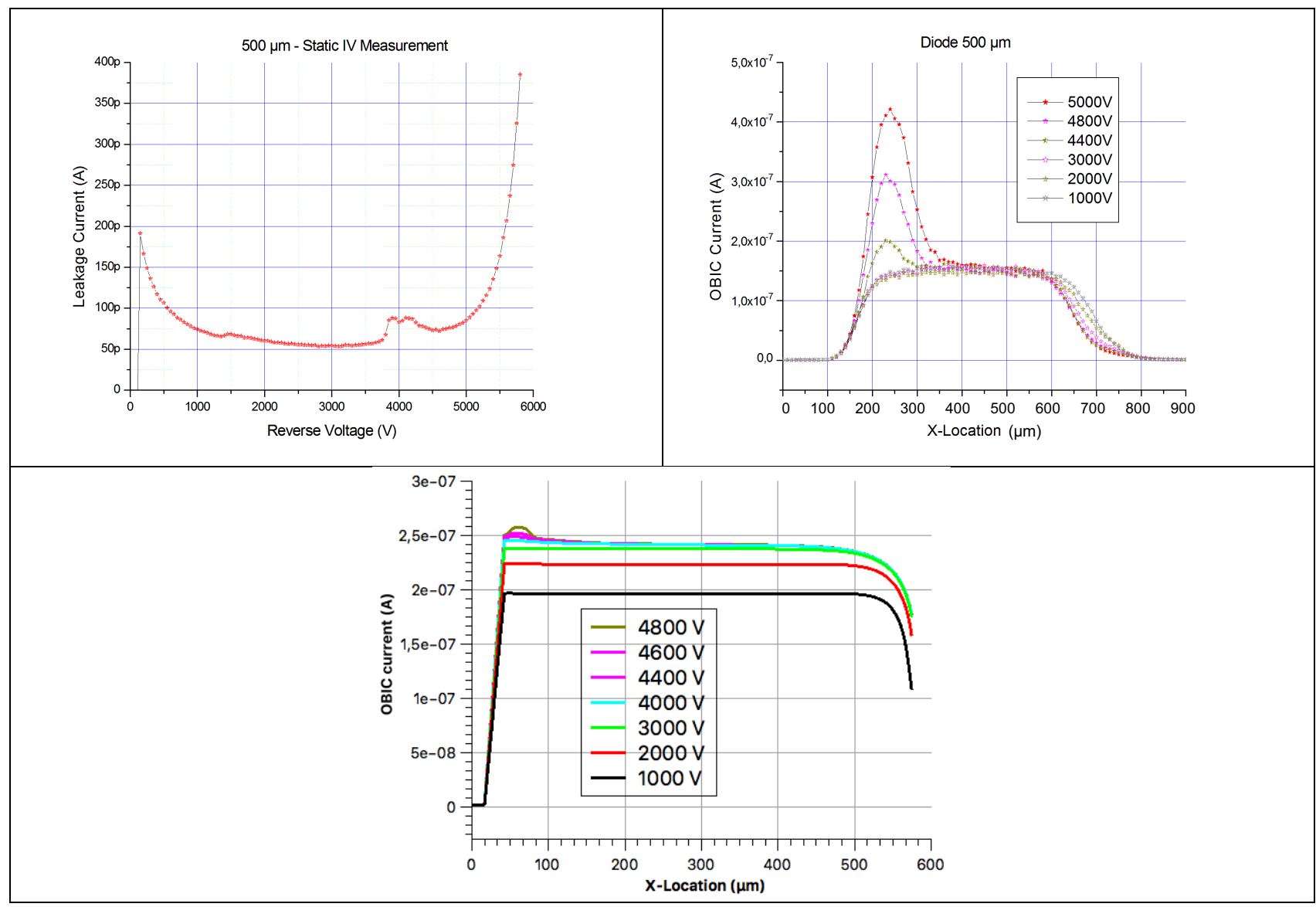

Fig. 12. Reverse experimental IV characteristics (upper left), 1D-sweeping OBIC measurements (upper right), 1D-sweeping OBIC simulations for several reverse biases (bottom) of the $\mathbf{5 0 0} \boldsymbol{\mu m}$ MESA-JTE protected diode.

The following figure show the $2 \mathrm{D}$ evolution of the OBIC current for six different voltages $(0,2000 \mathrm{~V}$, $3500 \mathrm{~V} 3800 \mathrm{~V} 4000$ and $4400 \mathrm{~V}$ ) on the $400 \mu \mathrm{m}$ MESA JTE +8 rings protected diode. The OBIC current is normalized to the maximum value found for each cartography. The full diode is scanned with a step of $100 \mu \mathrm{m}$ in both directions. Lack of OBIC signal on the upper part of each mapping is due to shadow of the connecting probe and the anode metallization. As the reverse bias increases, one can observe the birth of a peak value on the edge of the periphery $\left(\mathrm{V}_{\mathrm{R}}>3500 \mathrm{~V}\right)$ and then the complete side $\left(V_{R}=4400 V\right)$. These mappings give more information than the $1 \mathrm{D}$-sweeping, but are more timeconsuming.

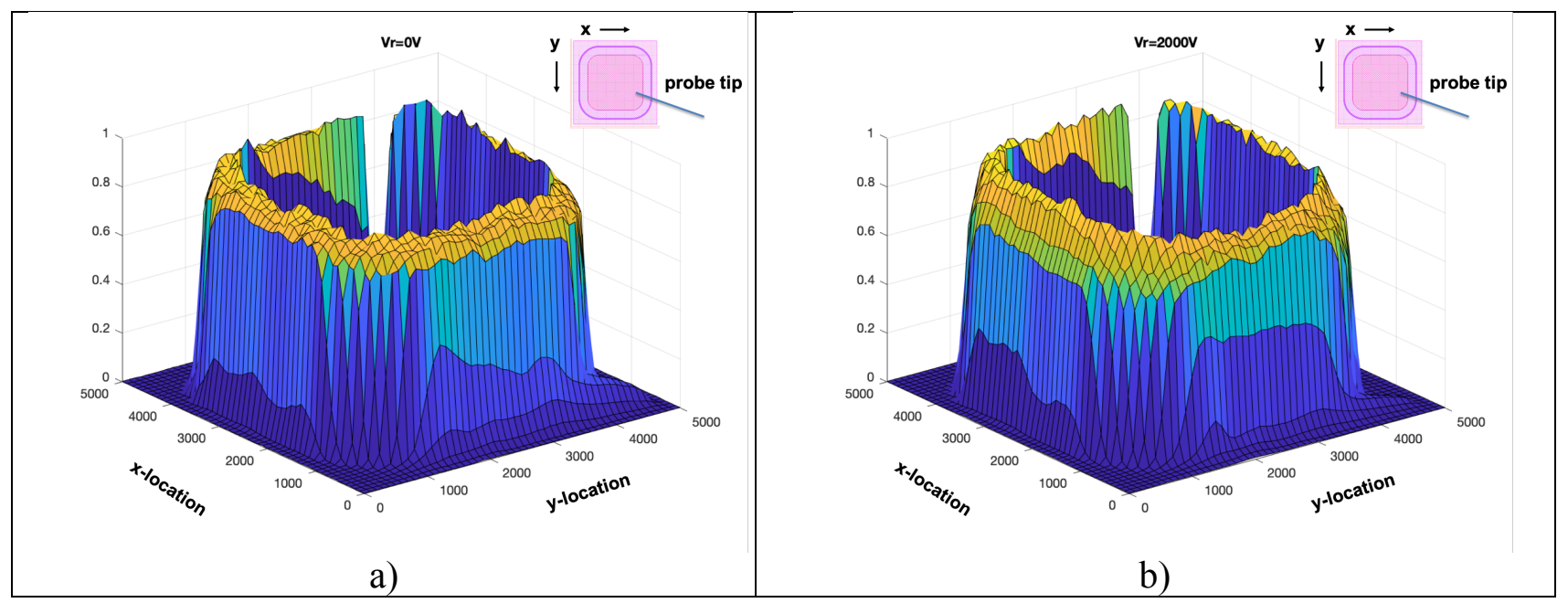




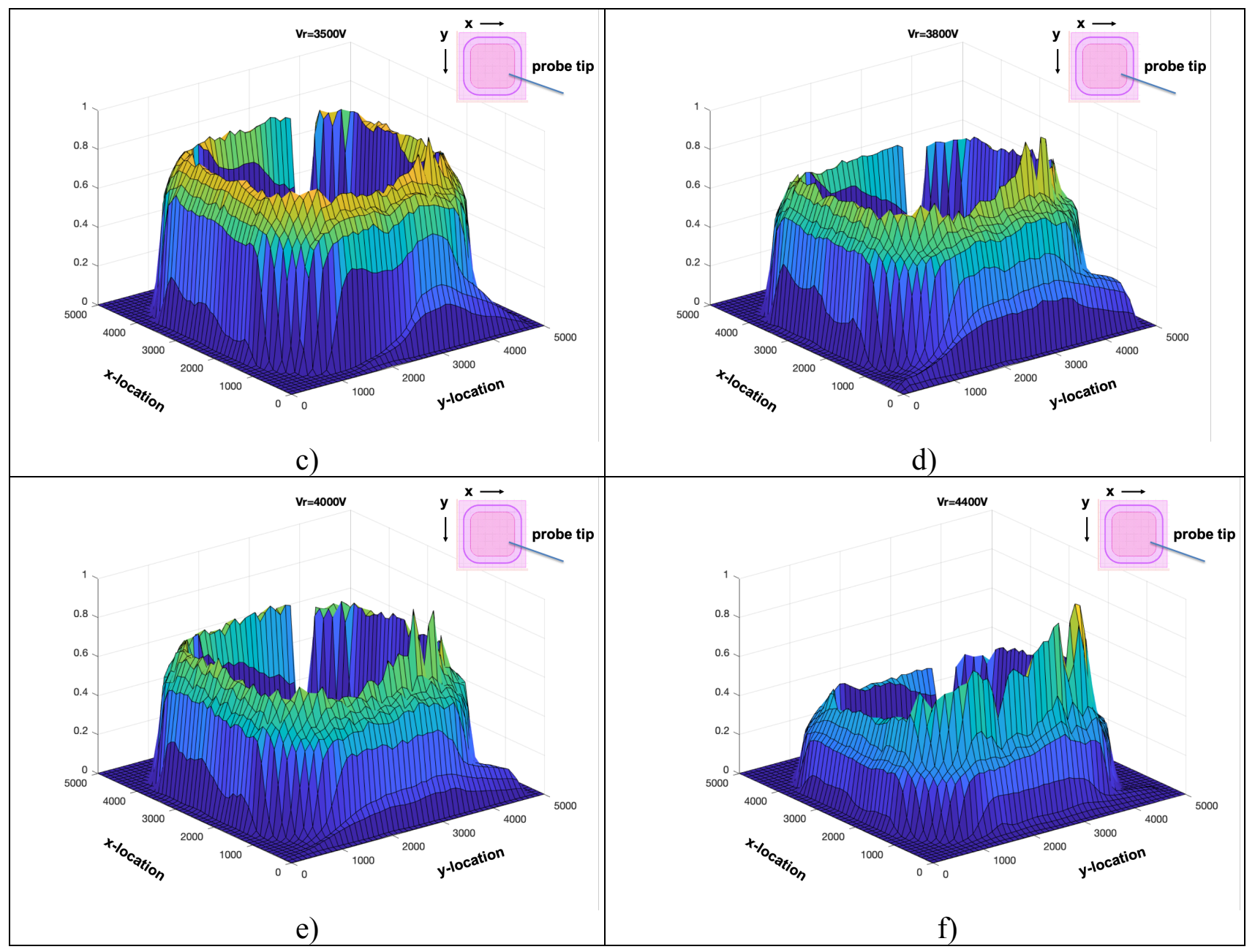

Fig 13. Experimental 2D-mapping of the OBIC current at different voltages a) $0 \mathrm{~V}$, b) 2000V, c) $3500 \mathrm{~V}$, d) $3800 \mathrm{~V}$, e) $4000 \mathrm{~V}$ and f) $4400 \mathrm{~V}$ ) for the $400 \mu \mathrm{m}$ MESA JTE +8 rings protected diode. The inset gives the $\mathrm{x}-\mathrm{y}$ direction and the position of the tip.

\section{5 - Measurements on other wide bandgap semiconductor samples}

Test measurements have been performed using the UV-Laser on GaN and Diamond devices. Twophotons absorption process takes place because the photon energy $\left(E_{\varphi}=h c / \lambda\right)$ is smaller than the bandgap energy $\left(\mathrm{E}_{\mathrm{G}}\right)$.

\section{1 - GaN Schottky diodes}

OBIC measurements have been carried out on Schottky GaN test structure as shown in Fig. 14.a). Structures were low reverse biased $(-10 \mathrm{~V})$ to avoid trapping effects and current collapse [13]. Current collapse in the GaN devices prevents high speed OBIC measurements: a delay is required after illumination by the optical beam for detrapping the carriers in the bulk. A 10 second delay was applied before carrying out the current measurement after moving to the next spot's location.

Figure 14.b) shows 1D-OBIC scan for low reverse voltage $\left(V_{R}=10 \mathrm{~V}\right)$. Results show an OBIC signal appearing at both edges of the MESA [14]. 


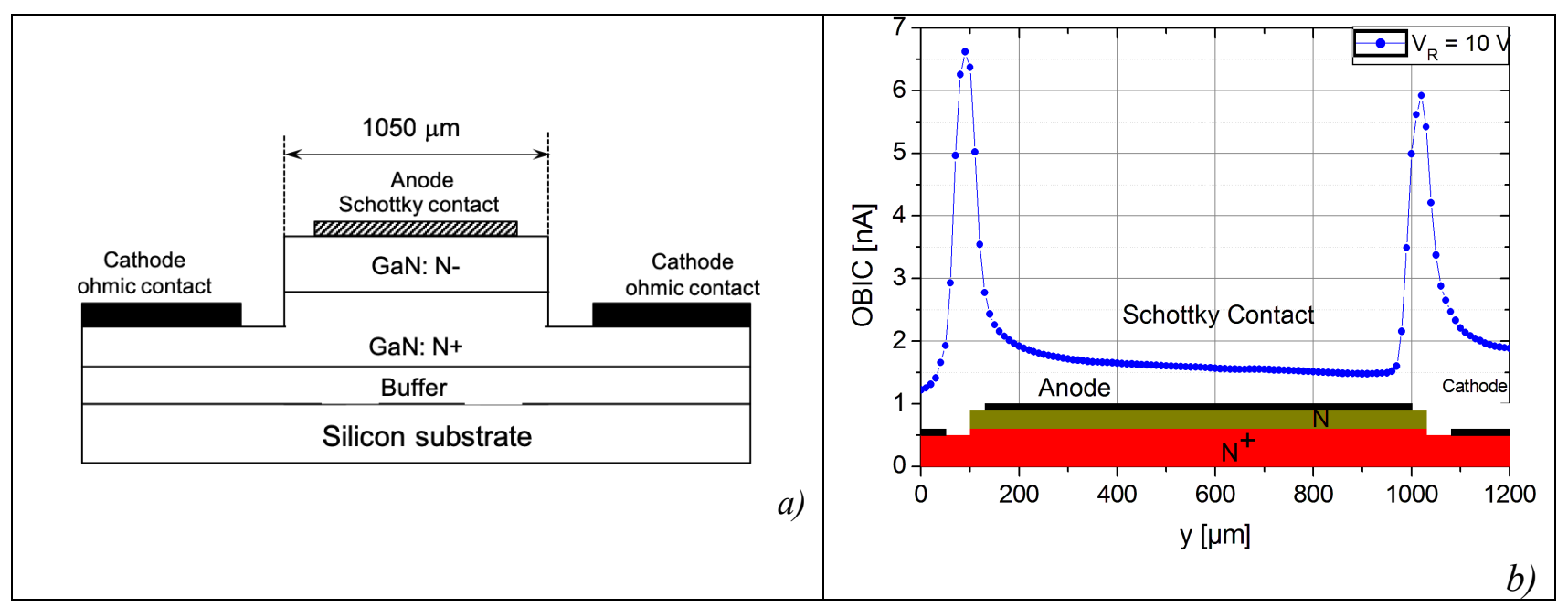

Fig. 14: Cross section a) and 1D-OBIC scan b) on Schottky GaN diode for a reverse voltage of $10 \mathrm{~V}$ using the UV laser. Laser beam was swept from left to right with a $10 \mu \mathrm{m}$ step.

\section{2 - Diamond Schottky diodes}

OBIC measurements under low voltage biasing $\left(\mathrm{V}_{\mathrm{R}}=5 \mathrm{~V}\right)$ have been also performed on Schottky diamond diodes with the UV laser source as shown in Fig 15. The circular shape (150 $\mu \mathrm{m}$ in diameter) of the device is clear; one can observe also the signal under the metallization due to the very small thickness of the metal on top of the diode (transparency effect).

The bandgap of the diamond $(5.45 \mathrm{eV})$ is larger than the photon energy $\left(\mathrm{E}_{\varphi}=\mathrm{hc} / \lambda=3.56 \mathrm{eV}\right)$ and hence the two-photon absorption process takes place. As for the $\mathrm{GaN}$ diode, a delay of $10 \mathrm{~s}$ is applied before the displacement of the laser beam.

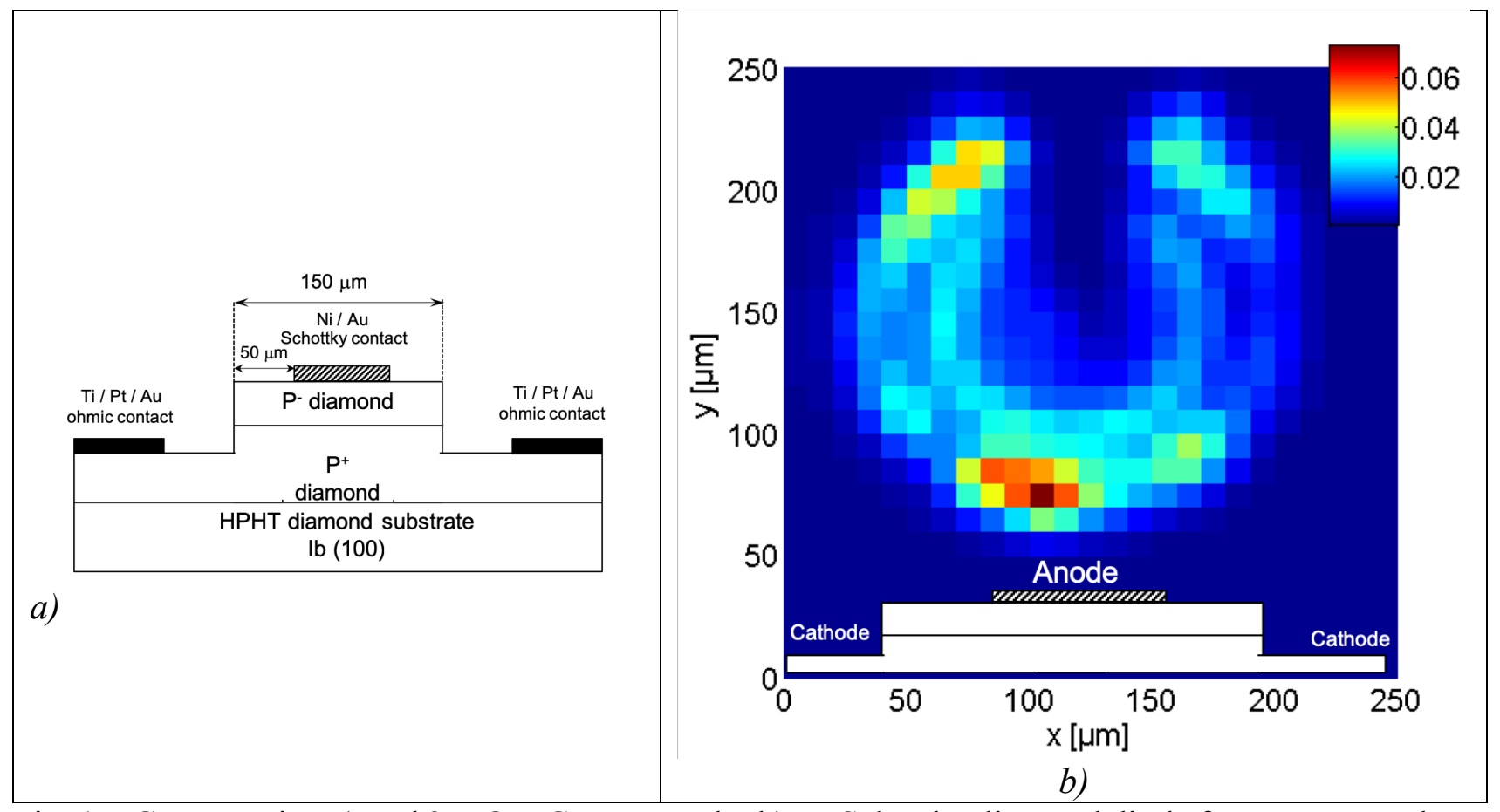

Fig. 15: Cross section a) and 2D-OBIC cartography b) on Schottky diamond diode for a reverse voltage of $5 \mathrm{~V}$ using the UV laser (diameter of the diode is $150 \mu \mathrm{m}$ ). Sweeping was fixed to $50 \mu \mathrm{m}$ in both directions [14].

\section{6 - Opportunities offered from OBIC}

\section{1 - Ionization coefficients determination}


As it was shown in the Simulation section, the determination of ionization rates is essential to predict breakdown voltage of devices. OBIC method is used to determine multiplication coefficient $\mathrm{M}$ which is defined as the ratio between OBIC and a voltage $\mathrm{V}$ and a reference voltage $\mathrm{V}_{0}$ (where there is no multiplication). Eq. 1 shows the expression of $\mathrm{M}$.

$$
M(V)=\frac{O B I C(V)}{O B I C\left(V_{0}\right)}=\frac{M_{n} J_{n}\left(z_{p}\right)+M_{p} J_{p}\left(z_{n}\right)+M_{S C R} J_{S C R}}{O B I C\left(V_{0}\right)}
$$

where $\mathrm{M}_{\mathrm{n}}\left(\mathrm{M}_{\mathrm{p}}, \mathrm{M}_{\mathrm{SCR}}\right)$ is electron (hole, $\left.\mathrm{SCR}\right)$ multiplication coefficient, $\mathrm{J}_{\mathrm{n}}$ and $\mathrm{J}_{\mathrm{p}}$ are minority carrier currents at the edges of the SCR, $\mathrm{J}_{\mathrm{SCR}}$ is the photo-generated current inside the SCR (figure 1). $\mathrm{M}_{\mathrm{n}}$, $\mathrm{M}_{\mathrm{p}}, \mathrm{M}_{\mathrm{SCR}}$ depend on the ionization rates, their expressions are given in [12]. Ionization rates $\alpha_{\mathrm{p}}$ (for holes) and $\alpha_{\mathrm{n}}$ (for electrons) are given by Eq. 2 [13].

$$
\alpha_{n, p}=A_{n, b} \exp \left(-B_{n, p} / E\right)
$$

where $A_{n, b}$ and $B_{n, p}$ are constants to be determined and $E$ is the electric field.

OBIC measurements are realized on Schottky diodes with an optical window. Experimental multiplication curve (inside the optical window) is found by considering $\mathrm{V}_{0}=1 \mathrm{~V}$. Ionization rates parameters are then adjusted to fit theoretical curve of $\mathrm{M}$ with experimental one by minimizing an error function $\Delta \mathrm{M}$ [15]-[17]. Table 2 displays the values of $\mathrm{A}_{\mathrm{n}, \mathrm{b}}$ and $\mathrm{B}_{\mathrm{n}, \mathrm{p}}$ for $4 \mathrm{H}-\mathrm{SiC}$ using both of laser sources (and then single- and two-photon absorption processes). Figure 16 shows ionization rates vs. the inverse of electric field for $4 \mathrm{H}-\mathrm{SiC}$. Comparison shows that the curves are close when using green

\begin{tabular}{|c|c|c|c|}
\hline & $\begin{array}{l}\text { UV } \\
\text { laser }\end{array}$ & Green laser & $\begin{array}{c}\text { Experimenta } \\
1\end{array}$ \\
\hline$A_{n}\left[10^{6} \mathrm{~cm}^{-1}\right]$ & 0.99 & 1.11 & \\
\hline $\begin{array}{l}B_{\mathbf{n}}\left[10^{7} \mathrm{~V} \cdot \mathrm{cm}^{-}\right. \\
\left.{ }^{-}\right]\end{array}$ & 1.29 & 1.22 & \\
\hline$A_{p}\left[10^{6} \mathrm{~cm}^{-1}\right]$ & 1.61 & 1.71 & \\
\hline $\begin{array}{l}B_{p}\left[10^{7} \mathrm{~V} \cdot \mathrm{cm}^{-}\right. \\
\left.{ }_{1}\right]\end{array}$ & 1.15 & 1.18 & \\
\hline$\Delta \mathbf{M}$ & 1.824 & 0.724 & \\
\hline $\mathbf{V}_{\text {BR }}[\mathbf{V}]$ & 62.2 & 59.2 & 58.8 \\
\hline $\mathrm{E}_{\mathbf{C}}\left[\mathbf{M V} \cdot \mathrm{cm}^{-1}\right]$ & 4.9747 & 4.9036 & \\
\hline
\end{tabular}
or UV laser.

Table 2. Parameters of ionization rates of $4 \mathrm{H}-\mathrm{SiC}$ using OBIC method with two different wavelengths [15]-[17].
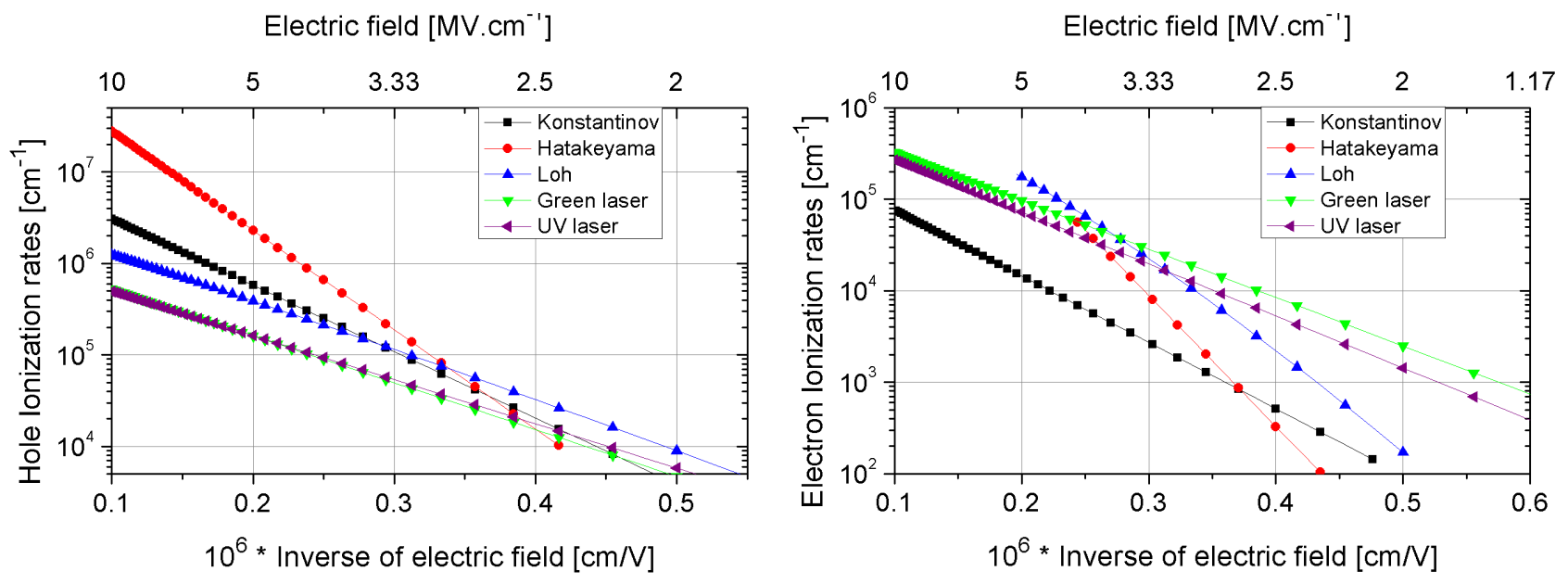

Fig. 16. Ionization rates a) hole and b) electron vs. inverse of electric field for $4 \mathrm{H}-\mathrm{SiC}$ using OBIC method with single- and two-photon absorption process, and compared to other authors. 
Comparison shows that the hole's ionization rates $\alpha_{\mathrm{p}}$ are greater than electron's ionization rates $\alpha_{\mathrm{n}}$ (as the other authors) but the ratio $\alpha_{\mathrm{p}} / \alpha_{\mathrm{n}}$ is about twice. Difference found between the authors is due to the doping levels of DUTs and the method used to extract ionization rates.

\section{2 - Lifetime extraction}

Lifetime of charge carriers is a key parameter for power devices, it allows to predict the static and dynamic losses of a junction. OBIC technique was used to determine minority carrier lifetime in $4 \mathrm{H}-$ $\mathrm{SiC}$ [18]. OBIC measurements were performed on JTE $(200 \mu \mathrm{m}$ long) protected PiN diode. At the edge of the JTE layer, the junction is supposed to be vertical, and the minority charge carriers are holes. When the laser beam scans the diode, the OBIC measured at the edge of the JTE decreases as a function of the minority carrier diffusion length $\mathrm{L}_{\mathrm{dp}}$ as shown in Eq. 3.

$$
O B I C(x)=u \exp \left(-\frac{x}{L_{d p}}\right)
$$

where $u$ is the optical generation rate.

Minority carrier lifetime $\tau_{p}$ is related to $L_{d p}$ and the diffusion coefficient of holes $D_{p}$ as shown in Eq. 4.

$$
\tau_{p}=\frac{L_{d p}{ }^{2}}{D_{p}}=\frac{q L_{d p}{ }^{2}}{k T \mu_{p}}
$$

where $\mathrm{k}$ is Boltzmann constant, $\mathrm{T}$ the temperature, $\mathrm{q}$ the electron charge and $\mu_{\mathrm{p}}$ the hole mobility. Figure 17 shows the logarithm of OBIC $\ln (\mathrm{OBIC})$ vs. the beam position signal for voltages between 0 and $700 \mathrm{~V}$. Referring to Eq. 4, this value is the inverse of $\mathrm{L}_{\mathrm{dp}}$, so the diffusion length of holes is then $14.7 \mu \mathrm{m}$. Using Eq. 4 with hole mobility of $115 \mathrm{~cm}^{2} . \mathrm{V}^{-1} \mathrm{~s}^{-1}$, the lifetime of holes found is $730 \mathrm{~ns}$.

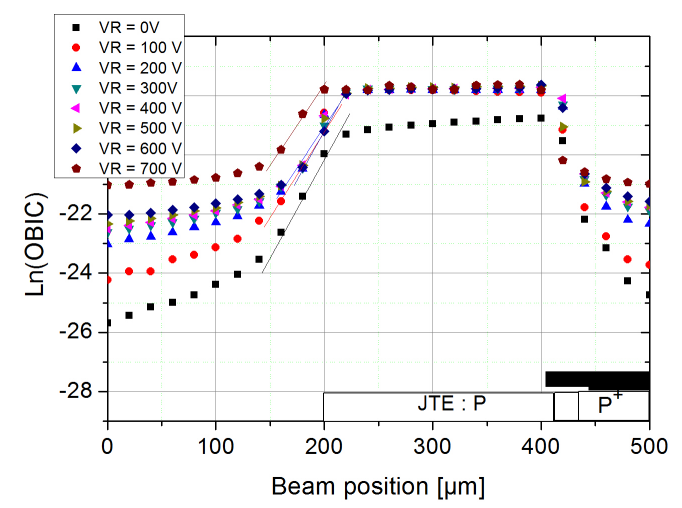

Fig. 17. $\operatorname{Ln}\left(\mathrm{I}_{\mathrm{OBIC}}\right)$ versus the beam position for $0 \leq \mathrm{V}_{\mathrm{R}} \leq 700 \mathrm{~V}$. Measurements were done on the lefthand side of the planar JTE protected diode.

\section{3 - Defect near the surface (Green laser mapping)}

OBIC measurements allow the detection of material defects, assuming that a defect is shown as a local variation of electric field. Figure 18 shows 2D-OBIC measurements on a diode with a defect located in the JTE area. This diode has a breakdown voltage of $300 \mathrm{~V}$. A local OBIC peak appears at the defect position. These results show that the OBIC technique is a non-destructive method to determine defects. 

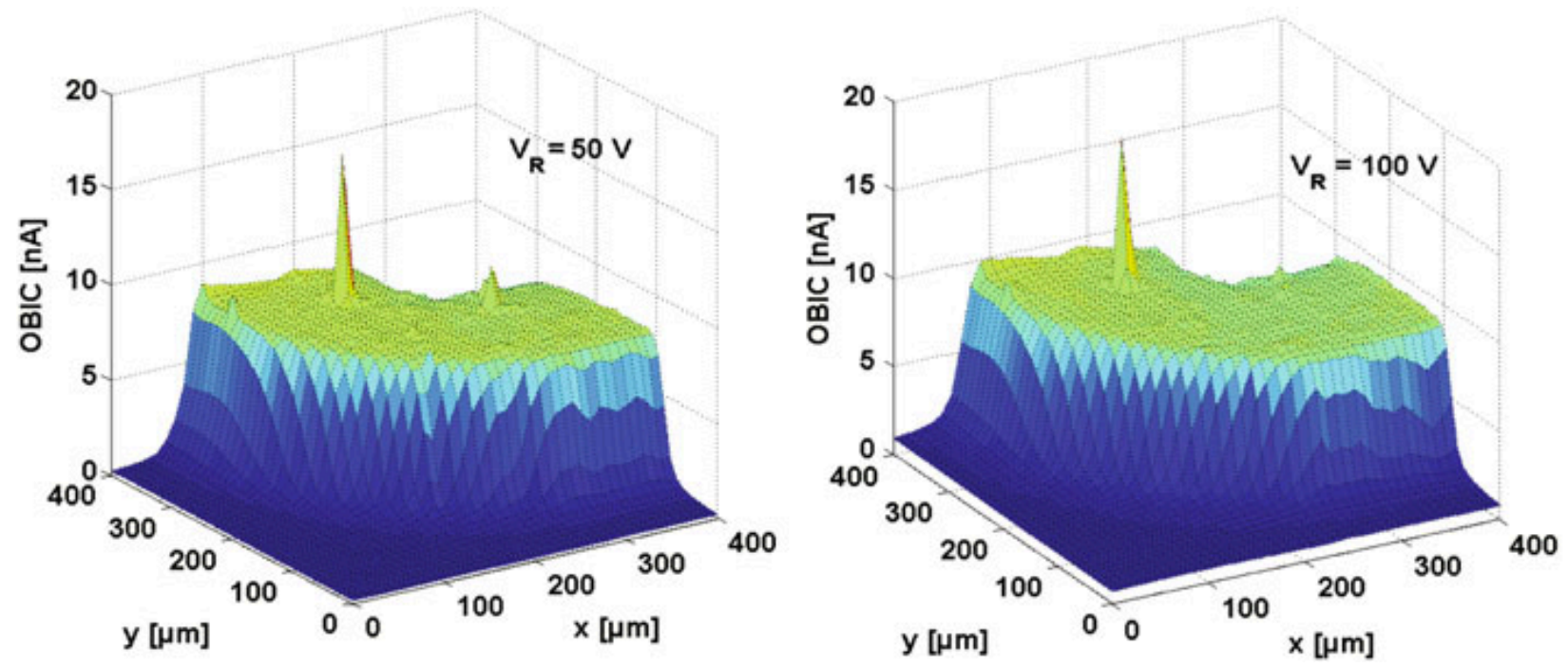

Fig. 18. 2D-OBIC cartography on JTE protected 4H-SiC bipolar diode as drawn in Fig 6, presenting a local defect using the green laser. Sweeping was fixed to $10 \mu \mathrm{m}$ in both directions.

\section{Conclusions}

This paper gives a full overview of what has already been achieved as well as the broad opportunities that the Optical Beam Induced Current measurement technique gives. Finite elements 2D simulations prove the theoretical validity of this technique. Moreover, for the first time high voltage (above $5 \mathrm{kV}$ ) OBIC measurements have been carried out and matched with simulations. Through this technique, the electrical field crowding at the edge of the anode and at the edge of the peripheral protection for lightly doped JTE and highly doped JTE, respectively, was shown. As such, this technique can be used to characterize the efficiency of the peripheral protection and help with its optimization process. Furthermore, it has been shown that OBIC measurements are possible with WBG materials such as $\mathrm{GaN}$ (gallium nitride) and C (diamond). Single or two-photon absorption process is chosen adequately. It is now open to other semiconductors. Other opportunities include: determination of the ionization coefficients, carrier lifetime extraction and noninvasive (microscopic) surficial-defect detection.

\section{Acknowledgments}

The authors would like to thank SuperGrid Institute (SGI) for providing high voltage SiC devices, Diamonix research program for providing the Diamond diode, Tours 2015 research program for providing GaN devices and finally for financial support the Caisse des Dépôts et Consignations (CDC) and BPI-France (FilSiC: Convention n ${ }^{\circ} \mathrm{O} 13953-410188$ ).

\section{References}

[1] K. Shenai, R. S. Scott, and B. J. Baliga, "Optimum semiconductors for high-power electronics," IEEE Trans. Electron Devices, vol. 36, no. 9, pp. 1811-1823, 1989.

[2] C. Raynaud, D. Tournier, H. Morel, and D. Planson, "Comparison of high voltage and high temperature performances of wide bandgap semiconductors for vertical power devices," Diam. Relat. Mater., vol. 19, no. 1, pp. 1-6, Jan. 2010.

[3] T. Mizushima et al., "Dynamic characteristics of large current capacity module using 16-kV ultrahigh voltage SiC flip-type n-channel IE-IGBT," in 2014 IEEE 26th International Symposium on Power Semiconductor Devices \& IC's (ISPSD), 2014, pp. 277-280.

[4] J. Millan, P. Godignon, X. Perpina, A. Perez-Tomas, and J. Rebollo, "A Survey of Wide Bandgap Power Semiconductor Devices," IEEE Trans. Power Electron., vol. 29, no. 5, pp. 2155-2163, 2014.

[5] K. Fukuda et al., "Development of Ultrahigh-Voltage SiC Devices," IEEE Trans. Electron Devices, vol. 62, no. 2, pp. 396-404, Feb. 2015. 
[6] N. Kaji, H. Niwa, J. Suda, and T. Kimoto, "Ultrahigh-voltage SiC p-i-n diodes with improved forward characteristics," IEEE Trans. Electron Devices, vol. 62, no. 2, pp. 374-381, 2015.

[7] R. Perret, Ed., Power electronics semiconductor devices. ISTE Ltd and John Wiley \& Sons, Inc, 2009.

[8] W. Choyke, H. Matsunami, and G. Pensl, "Silicon carbide: recent major advances," Springer Science \& Business Media, 2003.

[9] H. J. Leamy, "Charge collection scanning electron microscopy," J. Appl. Phys., vol. 53, no. 6, pp. R51-R80, Jun. 1982.

[10] C. Raynaud et al., "Optical beam induced current measurements: Principles and applications to SiC device characterization," Phys. Status Solidi Appl. Mater. Sci., vol. 206, no. 10, pp. 2273-2283, Oct. 2009.

[11] D. Planson et al., "Wide bandgap semiconductors for ultra high voltage devices. Design and characterization aspects," in Proceedings of the International Semiconductor Conference, CAS, 2014, pp. 35-40.

[12] T. C. A. D. Sentaurus, "Sdevice User Guide." 2018.

[13] M. Borga et al., "Impact of Substrate Resistivity on the Vertical Leakage, Breakdown, and Trapping in GaN-on-Si E-Mode HEMTs," IEEE Trans. Electron Devices, vol. 65, no. 7, pp. 2765-2770, Jul. 2018.

[14] H. Hamad, D. Planson, C. Raynaud, and P. Bevilacqua, "OBIC technique applied to wide bandgap semiconductors from $100 \mathrm{~K}$ up to $450 \mathrm{~K}$," Semicond. Sci. Technol., vol. 32, no. 5, p. 054001 , May 2017.

[15] H. Hamad, C. Raynaud, P. Bevilacqua, S. Scharnholz, and D. Planson, "Temperature Dependence of 4H-SiC Ionization Rates Using Optical Beam Induced Current," Mater. Sci. Forum, vol. 821-823, pp. 223-228, Jun. 2015.

[16] A. G. Chynoweth, "Uniform silicon p-n junctions. II. Ionization rates for electrons," J. Appl. Phys., vol. 31, no. 7, pp. 1161-1165, Jul. 1960.

[17] H. Hamad, C. Raynaud, P. Bevilacqua, S. Scharnholz, B. Vergne, and D. Planson, "Determination of 4H-SiC Ionization Rates Using OBIC Based on Two-Photon Absorption ," Mater. Sci. Forum, vol. 858, pp. 245-248, May 2016.

[18] T. Flohr and R. Helbig, "Determination of minority-carrier lifetime and surface recombination velocity by optical-beam-induced-current measurements at different light wavelengths," $J$. Appl. Phys., vol. 66, no. 7, pp. 3060-3065, Oct. 1989. 